\title{
RESTRUCTURING COMPANIES UNDER CRISIS A REAL CASE STUDY
}

\author{
Hezi Aviram SHAYB ${ }^{1}$ \\ ${ }^{1}$ Ph.D. Student at UTM University, Chişinău, Republic of Moldova, 168 Ștefan \\ cel Mare și Sfint Ave, Tel: +37322.237.861, Fax: +37322.237.861, \\ Former CEO at New Kopel Group, Bucharest, Romania, \\ Email: shaybhezi@gmail.com
}

\begin{abstract}
Nobody is planning to fail, but many companies are failing because of lack of planning. Real business experience showed during the years that crisis can be prevented, avoided or limited. If detected in time, the risks associated with the crisis can be mitigated and the effects can be diminished, with the condition that the actions required are done fast, in a sharp and accurate manner.

When it comes, a crisis brings intense level of pressure and under these conditions there is no time or room for mistakes. Delays, losing focus and lack of planning will bring a company one step away from failure.

The right way to deal with crisis, if required measures are not done in time, is to minimize the losses and reposition in the best way possible.

Analyzing the success stories of some of the biggest and strongest companies in the world, led to an important conclusion: the majority of these companies were in the situation to face huge crises that threatened their ability to survive in certain moments on their way to success.

With the right planning and by setting a proper organizational structure, the negative aspects of the crisis can be turned into benefits and opportunities for the company.

The most critical challenge for management is to assess the level of exposure to risk of the company and identify the key points to focus on in order to overcome the crisis and create value.

In order to set up a strong plan in dealing with crisis, a business organization needs reliable, efficient and effective tools and this is what this article is all about.
\end{abstract}

Keywords: lack of planning; right planning; crisis; exposure to risk; restructuring.

JEL Classification: $\mathrm{M}_{21}, \mathrm{O}_{21}$ 
Issue $3 / 2017$

Introduction: What We Are Going to Fix?

The goal of every business organization is to provide value for its stakeholders. When facing with crisis situations, this goal can no longer be served in a satisfactory level. When it escalates, the whole investment can be exposed.

In relation with the subject of crisis, the challenges that a company faces can be summarized as follows:

\section{- Lack of planning}

The majority of the companies that have setting procedures for business planning that give them the action plan for current business situations unfortunately don't have a planning for crisis situations.

\section{- The company's exposure to risk}

Most of the companies don't have a clear image about the risks they are exposed to and the level of those risks.

Not knowing where the problem came from could make it really difficult for the company's management to know how to approach the issue and how to find the solution.

\section{- Globalization and international effect}

Today, in our global world, companies are exposed and often affected by crises and events that are not necessarily associated to their core business, such as political, social or economic crises that take place in the international arena.

\section{- Existing pattern in human behaviour}

In general, people are resistant to changes, this can be affecting all levels of the company, starting with the employees and going to the highest level. Specially, managers tend to minimize the problems existing in their departments, not admitting the risks and the lack of control. More than that, when the crisis is coming, they tend to lose critical time before taking action by ignoring the level of exposure.

\section{- The complexity of restructuring}

Companies that passed the stage of risk assessment and know what needs to be changed, face the restructuring challenge.

Restructuring is a complex process of change that might affect all the departments and all the levels of the company.

The challenges faced during this process are connected to the people's resistance to change, the reallocation of the resources and the modification of the core structure of the business. 


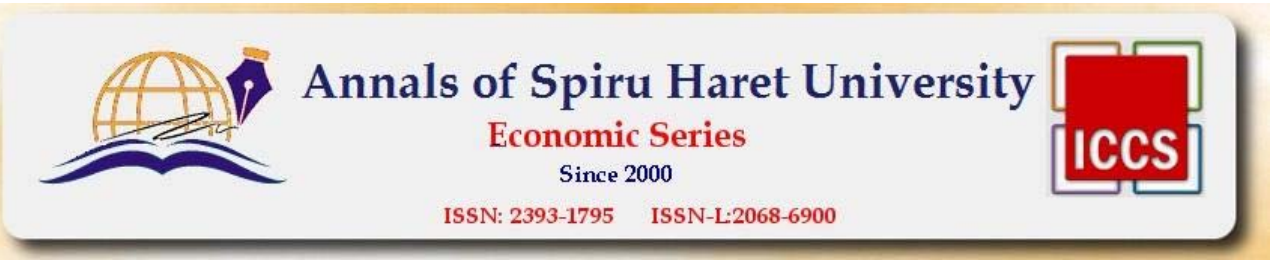

Issue $3 / 2017$

\section{Methodology: What Is the Solution?}

Following the theoretical model known as the cube matrix model "COSO ERM” (Enterprise Risk Management Integrated Framework), I have developed an applicable algorithm for assessing the level of the exposure to risk of a company, taking into consideration the three dimensional vectors presented on the cube. See Figure 1.

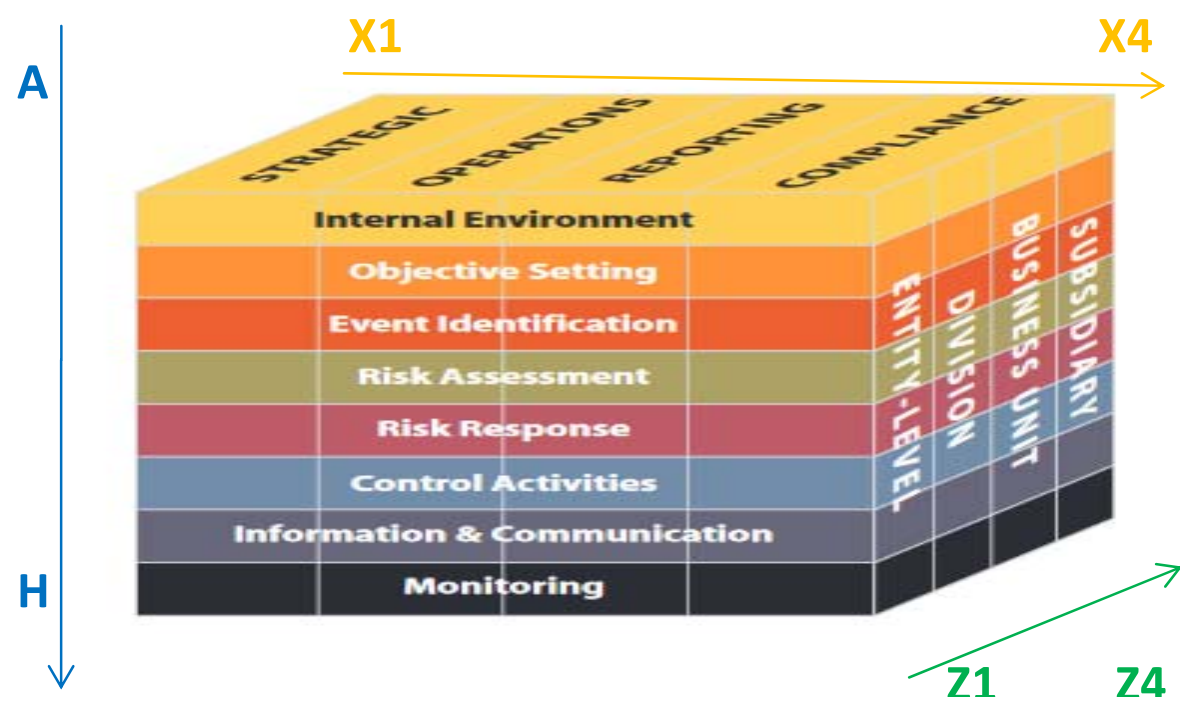

Figure no. 1. COSO ERM cube

The components of the cube can be explained as follows:

- Internal Environment - the tone of an organization, how risk is viewed and addressed by an entity's people, including risk management philosophy and risk appetite, integrity and ethical values, and the environment in which they operate.

- Objective Setting - management must set objectives and the chosen objectives must support and be aligned with the entity's mission and are consistent with its risk appetite.

- Event Identification - internal and external events affecting achievement of an entity's objectives must be identified, distinguishing between risks and opportunities. 
Issue $3 / 2017$

- Risk Assessment - risks are analyzed, considering likelihood and impact, as a basis for determining how they should be managed.

- Risk Response - avoiding, accepting, reducing, or sharing risk - developing a set of actions to align risks with the entity's risk tolerances and risk appetite.

- Control Activities - policies and procedures are established and implemented to help ensure the risk responses are effectively carried out.

- Information and Communication - relevant information is identified, captured, and communicated in a form and timeframe that enable people to carry out their responsibilities. Effective communication also occurs in a broader sense, flowing down, across, and up the entity.

- Monitoring - risk management is monitored and modifications are made as necessary. Monitoring is accomplished through ongoing management activities, separate evaluations, or both.

Within the context of a business entity's established mission or vision, management establishes strategic objectives, selects the strategy, and sets aligned objectives. The entity's objectives can be set in four categories:

- strategic - high-level goals, aligned with and supporting its mission;

- operations - effective and efficient use of its resources;

- reporting - reliability of reporting;

- compliance - compliance with applicable laws and regulations (internal and external).

The applicable algorithm that I have developed provides the solution based on:

\section{300 yes/no key questions project}

300 relevant questions (based on COSO ERM) are addressed regarding the existing situation of the company.

Each and every question represents a point of potential risk (if the answer is “no").

\section{Ranking the significance of the questions}

All though the 300 questions are relevant to the majority of business fields and companies, the significance of each and every one of them is different from one company to another. And also can be changed during time in certain companies.

In order to determine the weight of every question within a company, we need to evaluate every vector of the algorithm (X1-X4; Z1-Z4; A-H) from the most significant to the least. 
Issue 3/2017

A selected number of key persons in the company should evaluate these vectors. The average of their evaluation creates the weight.

\section{Mathematical algorithm}

The mathematical algorithm shows the company's exposure to risk and maps this exposure in certain activities.

The algorithm:

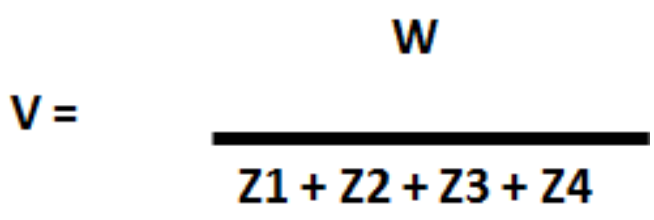

$W=$

$\mathrm{Z1} *$

$$
\begin{aligned}
& \left(X_{1} *(A 1+B 1+C 1+D 1+E 1+F 1+G 1+H 1)+\right. \\
& X 2 *(A 2+B 2+C 2+D 2+E 2+F 2+G 2+H 2)+ \\
& X 3 *(A 3+B 3+C 3+D 3+E 3+F 3+G 3+H 3)+ \\
& X 4 *(A 4+B 4+C 4+D 4+E 4+F 4+G 4+H 4))+
\end{aligned}
$$

$\mathrm{Z2} * \quad(\mathrm{X} 1 *(\mathrm{~A} 1+\mathrm{B} 1+\mathrm{C} 1+\mathrm{D} 1+\mathrm{E} 1+\mathrm{F} 1+\mathrm{G} 1+\mathrm{H} 1)+$

$\mathrm{X} 2 *(\mathrm{~A} 2+\mathrm{B} 2+\mathrm{C} 2+\mathrm{D} 2+\mathrm{E} 2+\mathrm{F} 2+\mathrm{G} 2+\mathrm{H} 2)+$

$(3 *(A 3+B 3+C 3+D 3+E 3+F 3+G 3+H 3)+$

$\mathrm{X} 4 *(A 4+B 4+\mathrm{C} 4+\mathrm{D} 4+\mathrm{E} 4+\mathrm{F} 4+\mathrm{G} 4+\mathrm{H} 4))+$

$\mathrm{Z} 3 * \quad(\mathrm{X} 1 *(\mathrm{~A} 1+\mathrm{B} 1+\mathrm{C} 1+\mathrm{D} 1+\mathrm{E} 1+\mathrm{F} 1+\mathrm{G} 1+\mathrm{H} 1)+$

$\mathrm{X} 2 *(\mathrm{~A} 2+\mathrm{B} 2+\mathrm{C} 2+\mathrm{D} 2+\mathrm{E} 2+\mathrm{F} 2+\mathrm{G} 2+\mathrm{H} 2)+$

$X_{3} *(A 3+B 3+C 3+D 3+E 3+F 3+G 3+H 3)+$

$\mathrm{X} 4 *(\mathrm{~A} 4+\mathrm{B} 4+\mathrm{C} 4+\mathrm{D} 4+\mathrm{E} 4+\mathrm{F} 4+\mathrm{G} 4+\mathrm{H} 4))+$

Z4* $\quad\left(X_{1} *(A 1+B 1+\mathrm{C} 1+\mathrm{D} 1+\mathrm{E} 1+\mathrm{F} 1+\mathrm{G} 1+\mathrm{H} 1)+\right.$

$\mathrm{X}_{2} *(\mathrm{~A} 2+\mathrm{B} 2+\mathrm{C} 2+\mathrm{D} 2+\mathrm{E} 2+\mathrm{F} 2+\mathrm{G} 2+\mathrm{H} 2)+$

$\mathrm{X}_{3} *(\mathrm{~A} 3+\mathrm{B} 3+\mathrm{C} 3+\mathrm{D} 3+\mathrm{E} 3+\mathrm{F} 3+\mathrm{G} 3+\mathrm{H} 3)+$

$\mathrm{X} 4 *(\mathrm{~A} 4+\mathrm{B} 4+\mathrm{C} 4+\mathrm{D} 4+\mathrm{E} 4+\mathrm{F} 4+\mathrm{G} 4+\mathrm{H} 4))$

Legend:

- $\mathrm{Qn}$ - answer value of the question (0 or 1 values) 
Issue $3 / 2017$

- $\mathrm{Rn}$ - weighted average in the cube given by the responders

An $=\mathbf{Q n} * \mathbf{R n}$

- $\mathbf{Z}$ - weighted average of the company levels in the cube

- $\mathbf{X}$ - weighted average in the objectives in the cube

- $\mathbf{W}$ - the sum of weighted average of the responses

- $\mathbf{V}$ - result of the company's health and stability - based on level, measures that can be taken to improve the company

\section{Algorithm Flowchart}

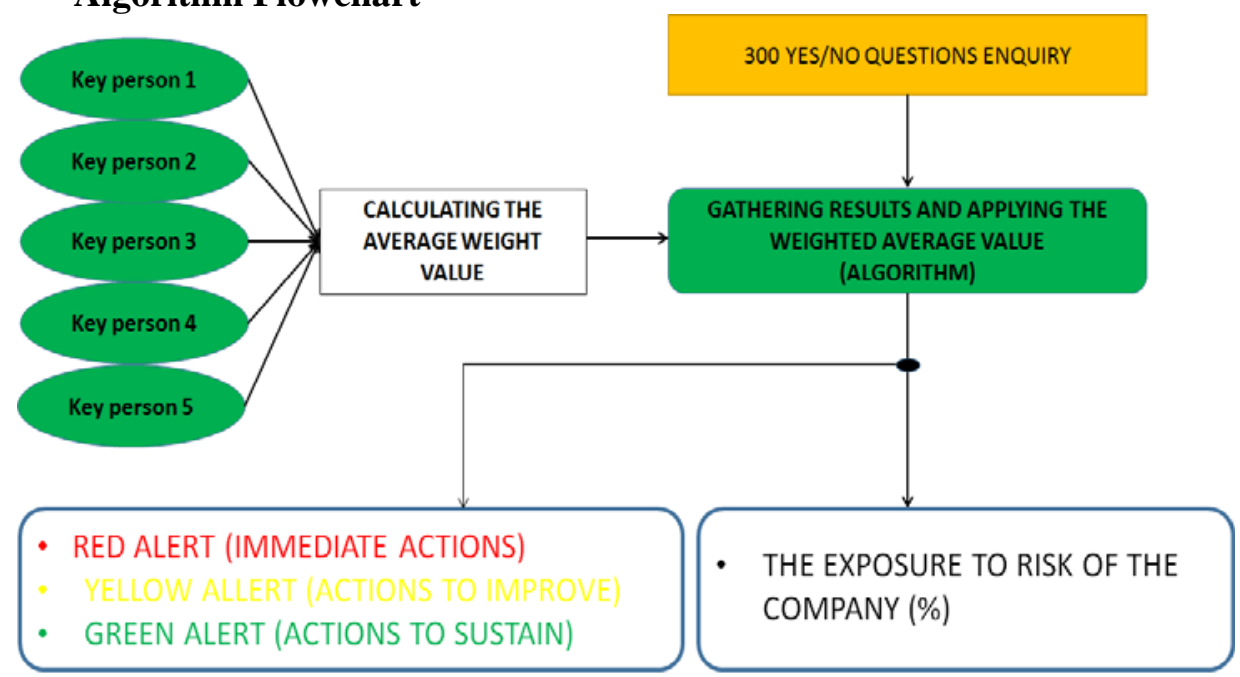

The finalized version of the mathematical algorithm will have an interface easy to understand, presenting the company's level of exposure to risk as a map.

The relevant questions and their answers which lead to the high, medium or normal percentage of risk exposure will be coloured in red, yellow or green.

Based on the result obtained throughout the algorithm, the company receives a percentage of exposure to risk, which will be illustrated as alerts, as follows: actions;

- Red alerts - in this places it is required for the company to take immediate points;

- Yellow alerts - actions for improvement are required on specific key

- Green alert - the company level of exposure is normal, actions taken before are reliable. 

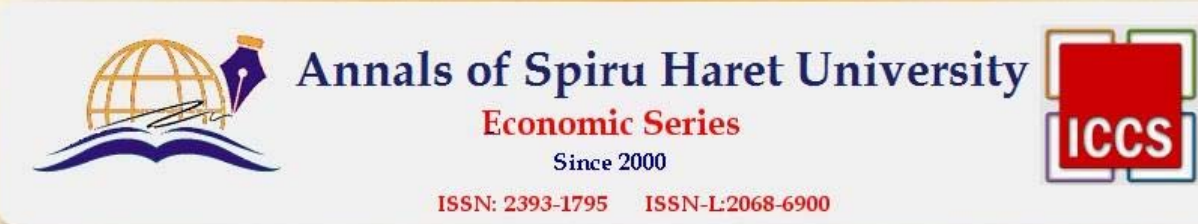

Issue $3 / 2017$

\section{Last but Not Least}

My research is a combination of academic knowledge of management under crisis and practical experience of managing companies under crisis in the last 20 years and handling crisis in general in the last 30 years, all set to create a practical and effective tool which will help decision makers pass "grey days".

\section{Author's background}

The author has a long experience in assessing risks and managing crisis.

He is a retired Major from the Israeli Navy (served in combat and intelligence positions).

He has almost 20 years of experience of CEO in Insurance and Automotive industry.

He is attending a Ph.D. program on "Restructuring companies under crisis" in UTM University. 
